PREVENTIVE HEALTHCARE:

TOPICAL ISSUES OF HEALTH RISK ANALYSIS

UDC [616-036.21: 578.834.1] (476)

DOI: $10.21668 /$ health.risk/2020.4.01.eng

Read

online

Research article

\title{
PREVALENCE OF BEHAVIORAL RISK FACTORS THAT CAUSE CONTAGION WITH COVID-19 AMONG POPULATION IN BELARUS: RESULTS OBTAINED VIA CROSS-SECTIONAL STUDY
}

\section{S.I. Sychik}

Scientific Practical Centre of Hygiene, 8 Akademicheskaya Str., Minsk, 220012, Belarus

\begin{abstract}
Our research objects were behavioral risk factors that could cause contagion with coronavirus infection (hereinafter called COVID-19).

Our research goal was to assess prevalence of behavioral risk factors that could cause contagion with COVID-19 among population in Belarus.

The present work contains results obtained via online questioning that included 7,590 respondents and employed a specifically designed questionnaire covering most common behavioral risk factors of contagion with COVID-19. The factors were related to adherence to recommendations on physical and social distancing, use of personal protective equipment, and sticking to personal hygiene rules; the questionnaire also asked respondents to give a subjective estimate of their health and whether they had specific symptoms typical for COVID-19. Data analysis involved assessing prevalence of behavioral risk factors, and occurrence of a relation between specific factors and values of prevalence ratio.

We determined prevalence of the most common behavioral risk factors and assessed to what extent risk factors influenced prevalence of subjective complaints by patients that they had symptoms typical for COVID-19. It was shown that certain behavioral risk factors authentically influenced prevalence of subjective symptoms of the disease. Subjective symptoms were more widely spread among respondents who regularly went to work as well as those whose family members regularly went to work or an educational establishment; among respondents who used public transport, went to shopping centers and catering facilities every day; among respondents who didn't keep social distance, didn't pay proper attention to personal hygiene, didn't use antiseptics, and had a habit to touch their face with their hands; among smoking respondents; among respondents who attended mass events, family and corporate parties; and also respondents whose relatives, close friends, or colleagues had returned from abroad.

Our research results can be used for carrying out information campaigns aimed at COVID-19 prevention; they can also give grounds for performing more profound studies on assessing contributions made by various behavioral factors into risks of contagion with COVID-19.

Key words: behavioral risk factors, questionnaire, coronavirus, COVID-19, pandemic, social distancing, personal hygiene, public health.
\end{abstract}

On January 30, 2020 WHO DirectorGeneral declared the current COVID-19 outbreak to be an emergency in public healthcare that was of international importance [1]. The declaration was made following conclusions made on a meeting held by the Committee on Emergencies in conformity with the International Sanitary Regulations. A new coronavirus strain had significant pandemic potential and it predetermined its rapid spread all over the world. As per the WHO data on June 23 2020 there were 8,974,795 confirmed COVID19 cases registered all over the world including 469,159 deaths [2].

Unprecedented actions aimed at preventing the infection spread were taken in every country as a response to this new biological threat of a scale previously unknown to the

(C) Sychik S.I., 2020

Sergey I. Sychik - Candidate of Medical Sciences, Associate Professor, Director (e-mail: rspch@rspch.by; tel.: +375 (17) 284-13-70; ORCID: https://orcid.org/0000-0002-5493-9799). 
world. Lockdown was introduced due to, among other things, strong emotional and motivation-related barriers that distorted people's adherence to following anti-epidemic recommendations voluntarily and it could result in substantial economic losses, both for each person and a state as a whole. Moreover, while there is no efficient vaccine, a probability still exists that in case lockdown is eased, a new infection outbreak will occur [3]. It indicates that there is a necessity to supplement lockdown measures with efficient actions aimed at raising people's adherence to behavioral models that allow them to protect themselves and their relatives and friends from contagion [4].

COVID-19 pandemic led to a wide-scale campaign held by public health organizations and aimed at spreading knowledge about individual protection from contagion such as hand hygiene, physical distancing, proper respiratory behavior, use of personal protection equipment and antiseptics, etc. However, despite all their attempts to promote knowledge on COVID-19 prevention, studies and questionings performed among population in different countries indicate that people are not well aware about ways of contagion, manageable and unmanageable factors that cause contagion risks and individual protection from infection [5-8].

A significant role in efficiency of antiepidemic activities implementation and ability to manage this emergency situation belongs to people's hygienic education and their readiness for conscious adherence to individual prevention. Given that, it is necessary to determine how well aware people are about COVID-19 as it will allow assessing whether they are ready to change their behavior and accept behavioral patterns recommended by public healthcare authorities; it will also allow determining priority tasks to be solved within hygienic education.

As per data obtained in several research works quick online questionings that require minimal efforts and can cover a lot of respondents during quite a short period of time can be a valuable instrument for assessing and monitoring knowledge and perception of an infection by people in the heat of an outbreak $[5,9]$.

Scientific studies aimed at studying pathogenesis, clinical signs, treatment procedures, and developing a vaccine for specific COVID-19 prevention have great significance in struggling against the pandemic; however, a study on behavioral risk factors aimed at more efficient management of epidemic processes is of equal importance for creating a system of anti-epidemic activities.

Our research goal was to assess prevalence of behavioral risk factors that could cause contagion with COVID-19 among people living in Belarus.

Data and methods. The study was conducted via an online questioning that seemed to us the most optimal way to obtain information on behavioral risk factors as it allowed us to collect initial data over a short period of time in a situation when certain limitations were imposed during the heat of the outbreak. The questioning involved using a specifically designed questionnaire that consisted of 23 questions covering basic behavioral risk factors that could cause COVID-19 contagion and were related to adherence to recommendations on physical and social distancing, use of personal protection equipment, and personal hygiene; there were also questions concerning respondents' subjective assessment of their health and occurrence of symptoms specific for COVID-19.

The online questioning was performed on the official website belonging to the Scientific and Practical Centre of Hygiene. Information about questioning was spread via social networks and mass media in order to attract as many respondents as possible.

Apart from data collection, the questioning was aimed at providing sanitary education for people and it was achieved via offering certain recommendations on how to correct behavioral risk factors; the recommendations were given to respondents after the online questioning was completed by them.

From April 17, 2020 to June 23, 2020 7,590 people took part in the questioning.

All the obtained data were statistically processed and analyzed with STATISTICA 13 
software package. Data analysis involved calculating absolute and relative frequencies. For extensive parameters, we calculated $95 \%$ confidence interval as per Wald procedure and the data were given as P (95\% CI). Significance of discrepancies between data that characterized qualitative properties was determined with contingency tables $2 \times 2$ basing on Pearson's correlation coefficient $\chi^{2}$. To assess what effects were produced by a certain factor, we calculated prevalence ratio (PR) and its confidence interval $(95 \% \mathrm{CI})$.

Critical significance value (p) in statistical hypotheses testing was taken at 0.05 .

Results and discussion. Social distancing (staying at home) and physical distancing when visiting a public place are most efficient measures that prevent COVID-19 contagion $[10,11]$. Having analyzed answers given by respondents to questions on social and physical distancing, we revealed that $52.9 \%$ (51.9-54.0) respondents continued working at their workplaces according to their normal routine, $26.2 \%$ (25.2-27.2) worked remotely, and $20.9 \%$ (20.0-21.8) didn't work or had to take a vacation. Most respondents (89.1\% (88.4-89.9)) lived in an apartment (living space) with their families or other people. And family members of those respondents who were able to not contact their colleagues working remotely or having a vacation also tended to remain at home more frequently than family members of people who still had to go to work, $59.8 \%(58.2-61.4)$ against $\quad 40.4 \% \quad(38.9-41.9) \quad\left(\chi^{2}=285.58\right.$, $p<0.001)$. Only $27.9 \%(26.9-28.9)$ respondents took public transport to travel around; the rest preferred a bicycle, their own car, or walking on foot; only $9.3 \%(8.7-10.0)$ gave a negative answer to a question about keeping physical distance from other people in public places, the rest kept a 1 meter distance $(48.6 \%$ (47.5-49.7)) or 1.5-2 meters distance $(42.1 \%$ (41.0-43.2).

Most respondents $(86.7 \%(85.9-87.5))$ didn't go to any catering facilities over the last two weeks; $5.7 \%$ (5.2-6.2) went to a restaurant or a café once in two weeks; and 7.6\% (7.0-8.2) once a week or more. $24.0 \%(23.0-25.0)$ went to a shop or a chemist's once a week or even less frequently; $53.8 \%(52.7-54.9)$ went shopping every 3-4 days; and $22.2 \%(21.3-23.1)$ did it every day. Only $2.2 \%(1.9-2.5)$ respondents took part in mass events (concerts, sport events, etc.) over the last two weeks, and $25.1 \%(24.1-26.1)$ took part in family parties, parties with friends or colleagues.

Having analyzed discrepancies in keeping social distancing by respondents who went to work and those who worked remotely/were on vacation, we revealed that respondents who didn't go to work were overall more committed to adhering to distancing rules. Thus, respondents who didn't contact their work team went to shops and chemist's more rarely as only $15.2 \%(14.0-16.4)$ people in this category went shopping daily against $28.5 \%(27.1-29.9)$ from those who went to work every day $\left(\chi^{2}=376.58\right.$, $p<0.001)$; they more rarely neglected physical distancing when being in a public place: $7.3 \%$ (6.5-8.2) respondents working remotely/being on vacation against $11.1 \%(10.1-12.1)$ among those who went to work every day $\left(\chi^{2}=97.09\right.$, $p<0.001)$; they also visited family, office, or friendly parties less frequently: $23.7 \%(22.3-25.1)$ respondents in this category against $26.4 \%$ (25.0-27.8) among those who went to work every day $\left(\chi^{2}=7.03, p=0.008\right)$.

Physical distancing is a significant prevention measure but other behavioral factors can also make a substantial contribution into risks occurrence. According to some data, a habit to touch one's T-zone on the face can also be important $[3,4]$. In our research the questioning revealed that $68.4 \%(67.4-69.5)$ respondents had this habit.

Several research works indicate that smoking considerably increases a possibility that COVID-19 will have aggravated clinical course; first of all, it is due to negative effects produced by tobacco smoking on the respiratory organs and immune system $[12,13]$. Besides, smoking is obviously related to regular contacts between hands and the facial T-zone and it can be an additional behavioral risk factor that can cause contagion. Our research revealed that $28.9 \%(27.9-29.9)$ respondents smoked. Smokers tended to touch their face more frequently than non-smokers, $72.7 \%$ 
(70.8-74.6) against $66.7 \%(65.4-68.0)$ accordingly $\left(\chi^{2}=26.08, p<0.001\right)$.

Sticking to personal hygiene rules to a great extent predetermines individual risks of COVID-19 contagion [13]. Respondents gave the following answers to questions concerning personal hygiene: $70.2 \%(69.2-71.2)$ washed their hands when it was necessary but not rarer than 5-6 times a day; $20.3 \%$ (19.4-21.2) did it approximately every 3 hours; and $9.6 \%$ (8.9-10.3), approximately every 6 hours. $54.0 \%$ (52.9-55.1) used antiseptics to treat their hands when it was necessary but not rarer than 4-5 times a day; $26.6 \%(25.6-27.6)$ did it 2 or 3 times a day; and $19.4 \%(18.5-20.3)$ respondents didn't use antiseptics at all. $39.3 \%$ (25.8-42.9) respondents from those who washed their hands only once in 6 hours didn't use antiseptics to treat their hands; $58.8 \%$ (57.5-60.1) respondents from those who washed their hands not rarer than 5-6 times a day also treated them with antiseptics not less than 4-5 times a day.

Proper respiratory behavior is also considered by the WHO to be effective prevention from COVID-19 contagion [14]. There was a question in the questionnaire, «How do you use handkerchiefs when it is necessary?» and $71.5 \%$ (70.5-72.5) respondents gave an answer «I use a Kleenex and throw it away immediately»; 9.6\% (8.9-10.3) stated that they used the same Kleenex several times; and $18.8 \%$ answered they used a cloth handkerchief.

Available scientific data allow us to assume that COVID-19 virus can spread over a distance exceeding 2 meters, and viruses can persist in a room as suspended particles for a long period of time thus extending a dangerous distance up to 10 meters and even more [15]. Given that, it is quite clear that airing plays a significant role in prevention. Our respondents were asked about airing; $25.3 \%$ (24.3-26.3) aired their apartments or offices at least once a day, $45.4 \%(44.3-46.3)$ did it 2 or 3 times a day, and $29.3(28.3-30.3)$ aired their apartments or offices not less than 5-6 times a day.

Use of medical face masks is also a part of prevention activities that allows control over infection spread; they can make for creat- ing a barrier for COVID-19 spread. Face masks can be worn by healthy people as personal protection equipment (to protect them during contacts with a sick person) or they can be a tool for control over an infection source (that is, when they are worn by sick people in order to prevent further infection spread). Still, an issue related to wearing medical face masks as personal protection equipment applied to protect the respiratory organs in everyday life is being discussed at the moment. Recommendations given by the WHO on use of masks to prevent COVID-19 spread state that now there are no convincing scientific data that directly indicate it is absolutely necessary for healthy people to widely use face masks everywhere [15]. On the other hand, there are available research works on spread of the infection by people who carry it without any symptoms or have just fallen sick and don't have any obvious symptoms but are still contagious; these research works imply that a role played by wearing face masks in preventing COVID-19 contagion can be underestimated [16-19]. Our online questioning revealed that a bit more than a half respondents $(58.7 \%(57.6-59.8))$ wore a mask when being in a public place and $54.3 \%$ (52.8-55.8) out of them changed it every $2-3$ hours if they used a three-layer mask and every 8 hours if they used a mask equipped with a filter. And here respondents who went to work gave a negative reply to the question about masks more frequently than those who worked remotely or was on vacation, $62.4 \%$ (60.9-63.9) against $55.4 \%(55.8-57.0)$ accordingly $\left(\chi^{2}=38.01, p<0.001\right)$.

Regular contacts with people who run high risks of contagion also increase a possibility of falling sick with the disease and require additional prevention activities. Thus, having a family member who is a medical worker and constantly contacts infected patients can considerably increase risks of contagion; contacts with people who have returned from regions where the situation with the epidemic is unfavorable in the beginning of the epidemic development also make a substantial contribution into individual risks occurrence [20]. As per data obtained via the questioning, 9.3\% 
(8.7-10.0) respondents lived with a person who worked in public healthcare, and $5.1 \%$ (4.6-5.6) respondents had close contacts with a person who came back from abroad or other regions in Belarus over the last two weeks. We analyzed subjective complaints made by the respondents about symptoms typical for COVID-19 (no sense of taste or smell, stuffy nose, running nose, cough, body ache, and fever) over the last two weeks; the analysis revealed that $42.1 \%(38.5-45.8)$ out of $39.3 \%$ (38.2-40.4) respondents who had those symptoms lived in one apartment with medical workers; there was no statistical significant discrepancy from a share of respondents who had those typical symptoms but didn't have medical workers in their family $(39.0 \%$ $(37.9-40.2))\left(\chi^{2}=2.55, p=0.11\right)$. But respondents having close contacts with people who had returned from abroad or other regions in Belarus had subjective complaints authentically more frequently than those who didn't have such contacts $(58.2 \%(53.3-63.1))$ against $38.3 \%$ (37.1-36.3)) accordingly) $\left(\chi^{2}=61.58, p<0.001\right)$ (PR 2.15 (95\% CI 1.77-2.62).

Having analyzed answers given by respondents who had medical workers in their families, we also revealed that they used a mask to protect their respiratory organs in public places more frequently than those who didn't have medical workers in their families, $65.5 \%(62.0-69.0))$ against $58.0 \%(57.6-58.4))$ accordingly $\left(\chi^{2}=14.91, p<0.001\right)$.

Commitment to prevention activities among people who live together with respondents also plays a significant role in contagion risks occurrence. Subjective complaints about typical symptoms were 1.28 (1.21-1.35) times more frequent among respondents living with people who tended to neglect personal and respiratory hygiene, didn't keep distancing and didn't use personal protection equipment in public places than among those living with people who adhered to recommendations on prevention. Respondents who were committed to prevention activities but lived with people who neglected them also authentically more frequently stated that they had contagion symptoms. Thus, respondents who wore a face mask in public places but lived with people who didn't adhere to personal hygiene rules and other recommendations on prevention had typical symptoms during the last two weeks authentically more frequently than respondents who lived alone or with people who adhered to recommended prevention activities, $50.5 \%(46.9-54.1)$ against $36.2 \%$ (34.7-37.8) accordingly $\left(\chi^{2}=53.61, p<0.001\right)$, PR 1.40 (1.28-1.52).

Data on influence exerted by different behavioral factors on a probability that subjective COVID-19 symptoms occur in a respondent are quite interesting; they are presented in Table 1.

Our research results indicate that a whole lot of behavioral risk factors authentically exert their influence on prevalence of subjective complaints about having typical COVID-19 symptoms. Subjective symptoms of the diseases were $1.2(1.13-1.27)$ times more frequent among respondents who went to work regularly; 1.24 (1.18-1.32) times more frequent among respondents whose family members went to work or study regularly; $1.15(1.08-1.22)$ times more frequent among respondents who took public transport to travel around the city; 1.26 (1.19-1.34) times more frequent among respondents who went shopping every day; 1.24 (1.15-1.33) times more frequent among respondents who went to catering facilities; 1.40 (1.30-1.51) times more frequent among respondents who didn't keep a proper physical distance when being in a public place; 1.13 (1.07-1.2) times more frequent among respondents who didn't pay enough attention to their hands hygiene; 1.11 (1.04-1.19) times more frequent among respondents who didn't use antiseptics to treat their hands; 1.49 (1.39-1.59) times more frequent among respondents who had a habit to touch their face with the hands; 1.25 (1.18-1.33) times more frequent among smoking respondents; 1.52 (1.39-1.66) times more frequent among respondents having close contact with people who came back from abroad or other regions in Belarus; 1.58 (1.39-1.78) times more frequent among respondents who visited mass events; and 1.22 (1.15-1.30) times more frequent among respondents who visited family or office parties. 
Table 1

Influence exerted by behavioral risk factors on a probability of subjective COVID-19 symptoms occurrence

\begin{tabular}{|c|c|c|c|c|}
\hline No. & Analyzed factors & \begin{tabular}{|c|} 
A share of respondents \\
who state they have \\
specific COVID-19 \\
symptoms, \%
\end{tabular} & $\chi^{2}$ & PR \\
\hline 1. & $\begin{array}{l}\text { Going to work as usual } \\
\text { Working remotely/vacation }\end{array}$ & $\begin{array}{l}42.6(41.1-44.1)^{*} \\
35.6(34.0-37.2)\end{array}$ & 39.46 & $\begin{array}{c}1.20 \\
(1.13-1.27)\end{array}$ \\
\hline 2. & $\begin{array}{l}\text { Respondent's family members who live with him/her go } \\
\text { to work/study as usual } \\
\text { Respondent's family members who live with him/her } \\
\text { work remotely/are on vacation }\end{array}$ & $\begin{array}{l}43.5(41.9-45.1)^{*} \\
35.0(33.5-36.5)\end{array}$ & 57.95 & $\begin{array}{c}1.24 \\
(1.18-1.32)\end{array}$ \\
\hline 3. & $\begin{array}{l}\text { Taking public transport to go around } \\
\text { Using a car, a bicycle, or walking }\end{array}$ & $\begin{array}{l}43.4(41.3-45.5)^{*} \\
37.7(36.4-39.0)\end{array}$ & 20.67 & $\begin{array}{c}1.15 \\
(1.08-1.22)\end{array}$ \\
\hline 4. & $\begin{array}{l}\text { Going shopping or to a chemist's every day } \\
\text { Going shopping or to a chemist's every three days or rarer }\end{array}$ & $\begin{array}{l}46.9(44.5-49.3)^{*} \\
37.1(35.9-38.3) \\
\end{array}$ & 53.15 & $\begin{array}{c}1.26 \\
(1.19-1.34)\end{array}$ \\
\hline 5. & $\begin{array}{l}\text { Going to catering facilities } \\
\text { Not going to catering facilities }\end{array}$ & $\begin{array}{l}47.1(44.0-50.2)^{*} \\
38.1(36.9-39.3)\end{array}$ & 29.81 & $\begin{array}{c}1.24 \\
(1.15-1.33) \\
\end{array}$ \\
\hline 6. & $\begin{array}{l}\text { Not keeping a proper physical distance } \\
\text { Keeping a proper physical distance }\end{array}$ & $\begin{array}{l}53.2(49.5-56.9)^{*} \\
37.9(36.8-39.1)\end{array}$ & 62.97 & $\begin{array}{c}1.40 \\
(1.30-1.51)\end{array}$ \\
\hline 7. & $\begin{array}{l}\text { Not wearing a mask in public places } \\
\text { Wearing a mask in public places }\end{array}$ & $\begin{array}{l}40.4(38.7-42.1) \\
38.5(37.1-39.9)\end{array}$ & 2.73 & - \\
\hline 8. & $\begin{array}{l}\text { Washing hands every } 3 \text { hours or rarer } \\
\text { Washing hands when necessary but not less than } \\
5-6 \text { times a day }\end{array}$ & $\begin{array}{l}42.8(40.8-44.8)^{*} \\
37.8(36.5-39.1)\end{array}$ & 16.81 & $\begin{array}{c}1.13 \\
(1.07-1.20)\end{array}$ \\
\hline 9. & $\begin{array}{l}\text { Not using antiseptics to treat hands } \\
\text { Using antiseptics to treat hands }\end{array}$ & $\begin{array}{l}42.7(40.2-45.2)^{*} \\
38.5(37.3-39.7)\end{array}$ & 9.07 & $\begin{array}{c}1.11 \\
(1.04-1.19)\end{array}$ \\
\hline 10. & $\begin{array}{l}\text { A habit to touch one's face with the hands } \\
\text { No habit to touch one's face with the hands }\end{array}$ & $\begin{array}{l}43.8(42.5-45.2)^{*} \\
29.5(27.7-31.3)\end{array}$ & 140.91 & $\begin{array}{c}1.49 \\
(1.39-1.59) \\
\end{array}$ \\
\hline 11. & $\begin{array}{l}\text { Smoking } \\
\text { No smoking }\end{array}$ & $\begin{array}{l}45.9(43.8-48.0)^{*} \\
36.6(35.3-37.9)\end{array}$ & 56.74 & $\begin{array}{c}1.25 \\
(1.18-1.33) \\
\end{array}$ \\
\hline 12. & $\begin{array}{l}\text { There are medical workers among family members who } \\
\text { live together with a respondent } \\
\text { There are no medical workers among family members } \\
\text { who live together with a respondent }\end{array}$ & $\begin{array}{l}42.1(38.5-45.8) \\
39.0(37.9-40.2)\end{array}$ & 2.55 & - \\
\hline 13. & $\begin{array}{l}\text { Close contacts with people who returned from abroad or } \\
\text { other regions in Belarus over the last two weeks } \\
\text { No close contacts with people who returned from abroad } \\
\text { or other regions in Belarus over the last two weeks }\end{array}$ & $\begin{array}{l}58.2(53.3-63.1)^{*} \\
38.3(37.2-39.4)\end{array}$ & 61.58 & $\begin{array}{c}1.52 \\
(1.39-1.66)\end{array}$ \\
\hline 14. & $\begin{array}{l}\text { A visit to a mass event (s) over the last two weeks } \\
\text { No visits to a mass event (s) over the last two weeks }\end{array}$ & $\begin{array}{l}61.2(53.9-68.5)^{*} \\
38.8(37.7-39.9) \\
\end{array}$ & 34.88 & $\begin{array}{c}1.58 \\
(1.39-1.78) \\
\end{array}$ \\
\hline 15 . & $\begin{array}{l}\text { Visiting a family / an office party etc, over the last } \\
\text { two weeks } \\
\text { No visits to a family / an office party etc, over the last } \\
\text { two weeks }\end{array}$ & $\begin{array}{l}45.5(43.3-47.7)^{*} \\
37.2(35.9-38.5)\end{array}$ & 41.53 & $\begin{array}{c}1.22 \\
(1.15-1.30)\end{array}$ \\
\hline
\end{tabular}

Not e : * means discrepancies are statistically significant at $\mathrm{p}<0.05$.

Conclusions. Results obtained in the present research can be used as a basis for information campaigns carried out by public healthcare organizations and mass media and aimed at clarifying how to prevent COVID-19 and other acute respiratory viral diseases. The results indicate that it is necessary to develop and implement specific sanitary education 
programs in order to provide people with useful knowledge and to create more responsible attitudes towards anti-epidemic activities. When developing such programs, it is obligatory to apply a complex approach that allows taking into account all behavioral risk factors since our research results revealed that most respondents were influenced by several factors simultaneously. Our research also allowed revealing that a family produced a significant effect on personal behavior and commitment to preventive activities and it also should be taken into account when developing approaches to individual prevention.
Our results can also be applied for monitoring over behavioral risk factors in order to make operative managerial decisions in a situation when an epidemic process is developing dynamically; they can be a basis for more profound examinations focusing on assessing a contribution made by different behavioral factors into risks of COVID-19 contagion.

Funding. Research has been accomplished to use of funds belonging to the Scientific and Practical Center for Hygiene.

Conflict of interest. The authors declare there is no any conflict of interests.

\section{References}

1. Updated WHO recommendations for international traffic in relation to COVID-19 outbreak. World health organization, 2020. Available at: https://www.who.int/ith/2019-nCoV_advice_for_international_traffic-rev/ru/ (23.06.2020).

2. WHO Coronavirus Disease (COVID-19) Dashboard. World health organization, 2020. Available at: https://covid19.who.int/ (23.06.2020).

3. West R., Michie S., Rubin G.J., Amlôt R. Applying principles of behaviour change to reduce SARS-CoV-2 transmission. Nature Human Behaviour, 2020, vol. 4, pp. 451-459. DOI: 10.1038/ s41562-020-0887-9

4. West R., Michie S. Routes of transmission of SARS-CoV-2 and behaviours to block it: a summary. Qeios, 2020, vol. 7, 4 p. DOI: 10.32388/F6M5CB

5. Geldsetzer P. Use of Rapid Online Surveys to Assess People's Perceptions During Infectious Disease Outbreaks: A Cross-sectional Survey on COVID-19. J Med Internet Res, 2020, vol. 22, no. 4, pp. e18790. DOI: $10.2196 / 18790$

6. Singh D.R., Sunuwar D.R., Karki K., Ghimire S., Shrestha N. Knowledge and Perception Towards Universal Safety Precautions During Early Phase of the COVID-19 Outbreak in Nepal. Journal of Community Health, 2020, no. 45, pp. 1116-1122. DOI: 10.1007/s10900-020-00839-3

7. Zhong B.-L., Luo W., Li H.-M., Zhang Q.-Q., Liu X.-Ge, Li W.-T., Li Y. Knowledge, attitudes, and practices towards COVID-19 among Chinese residents during the rapid rise period of the COVID-19 outbreak: a quick online cross-sectional Survey. International Journal of Biological Sciences, 2020, vol. 16 , no. 10 , pp. $1745-1752$. DOI: $10.7150 /$ ijbs. 4522

8. Azlan A.A., Hamzah M.R., Sern T.J., Hadi Ayub S., Mohamad E. Public knowledge, attitudes and practices towards COVID-19: A cross-sectional study in Malaysia. Plos One, 2020, vol. 15, № 5, pp. e0233668. DOI: 10.1371/journal.pone.0233668

9. Ali S.H., Foreman J., Capasso A., Jones A.M., Tozan Y., Di Clemente R.J. Social media as a recruitment platform for a nationwide online survey of COVID-19 knowledge, beliefs, and practices in the United States: methodology and feasibility Analysis. BMC Medical Research Methodology, 2020, no. 20, pp. 116. DOI: $10.1186 / \mathrm{s} 12874-020-01011-0$

10. Jarvis C.I., Zandvoort K.V., Gimma A., Prem K., CMMID COVID-19 working group, Klepac P., Rubin G.J., Edmunds W.J. Quantifying the impact of physical distance measures on the transmission of COVID-19 in the UK. BMC Medicine, 2020, no. 18, pp. 124. DOI: 10.1186/s12916-020-01597-8

11. Chu D.K., Ak1 E.A., Duda S., Yaacoub S., Solo K., Schünemann H.J. [et al.] Physical distancing, face masks and eye protection to prevent person-to-person transmission of SARS-CoV-2 and COVID-19: a systematic review and meta-analysis. Lancet, 2020, vol. 395, no. 10242, pp. 1973-1987. DOI: $10.1016 / \mathrm{S} 0140-6736(20) 31142-9$

12. Vardavas C.I., Nikitara K. COVID-19 and smoking: A systematic review of the evidence. Tob. Induc. Dis, 2020, no. 18, pp. 20. DOI: 10.18332/tid/119324 
13. Gasmi A., Noor S., Tippairote T., Dadar M., Menzel A., Bjørklund G. Individual risk management strategy and potential therapeutic options for the COVID-19 pandemic. Clinical Immunology, 2020, no. 215, pp. 108409. DOI: 10.1016/j.clim.2020.108409

14. Advice on the use of masks in the context of COVID-19: interim guidance, updated 5 June 2020. World Health Organization, 2020, 20 p.

15. Setti L., Passarini F., De Gennaro G., Barbieri P., Grazia Perrone M., Borelli M., Palmisani J., Di Gilio A. [et al.]. Airborne Transmission Route of COVID-19: Why 2 Meters/6 Feet of Inter-Personal Distance Could Not Be Enough. Int. J. Environ. Res. Public Health, 2020, vol. 17, no. 8, pp. 2932. DOI: $10.3390 /$ ijerph17082932

16. Yu P., Zhu J., Zhang Z., Han Y. A Familial Cluster of Infection Associated with the 2019 Novel Coronavirus Indicating Possible Person-to-Person Transmission During the Incubation Period. J Infect Dis, 2020, vol. 221, no. 11, pp. 1757-1761. DOI: 10.1093/infdis/jiaa077

17. Arons M.M., Hatfield K.M., Reddy S.C., Kimball A., James A., Jacobs J.R., Taylor J., Spicer K. [et al.]. Presymptomatic SARS-CoV-2 Infections and Transmission in a Skilled Nursing Facility. $N$ Engl $J$ Med, 2020, vol. 382, no. 22, pp. 2081-2090. DOI: 10.1056/NEJMoa2008457

18. Pan X., Chen D., Xia Y., Wu X., Li T., Ou X., Zhou L., Liu J. Asymptomatic cases in a family cluster with SARS-CoV-2 infection. Lancet Infect Dis, 2020, vol. 20, no. 4, pp. 410-411. DOI: 10.1016/S1473-3099(20)30114-6

19. Eikenberry S.E., Mancuso M., Iboi E., Phan T., Eikenberry K., Kuang Y., Kostelich E., Gumel A.B. To mask or not to mask: Modeling the potential for face mask use by the general public to curtail the COVID-19 pandemic. Infectious Disease Modelling, 2020, vol. 5, pp. 293-308. DOI: 10.1016/j.idm.2020.04.001

20. Chou R., Dana T., Buckley D.I., Selph S., Fu R., Totten A.M. [et al.]. Epidemiology of and Risk Factors for Coronavirus Infection in Health Care Workers. A Living Rapid Review. Annals of Internal Medicine, 2020, vol. 21, no. 173 (2), pp. 120-136. DOI: 10.7326/M20-1632

Sychik S.I. Prevalence of behavioral risk factors that cause contagion with COVID-19 among population in Belarus: results obtained via cross-sectional study. Health Risk Analysis, 2020, no. 4, pp. 4-11. DOI: 10.21668/health.risk/2020.4.01.eng

Received: 14.07 .2020

Accepted: 09.11.2020

Published: 30.09.2020 